\title{
PENGELOLAAN REKAM MEDIS RAWAT INAP DI PUSKESMAS
}

\author{
Harjanti $^{1^{*}}$; Astri Sri Wariyanti² \\ 1, 2 STIKes Mitra Husada Karanganyar; Papahan, Tasikmadu, Karanganyar \\ Jl. Brigjen Katamso Barat, Gapuran, Papahan Indah, Karanganyar, Jawa Tengah
}

\begin{abstract}
Abstrak
Pengelolaan Rekam Medis Rawat Inap di Puskesmas belum terdapat ruang penyimpanan khusus untuk Dokumen Rekam Medis (DRM). Kerahasiaan DRM belum terjamin dengan baik karena DRM ditaruh diatas almari dan diikat berdasarkan tanggal kunjungan serta ruangan dengan mudah diakses oleh semua orang. Tujuan penelitian menganalisis pengelolaan Rekam Medis Rawat Inap di Puskesmas. Rancangan penelitian yang digunakan adalah penelitian Kualitatif. Pengumpulan data dengan wawancara, observasi dan studi dokumentasi. Keabsahan data menggunakan triangulasi sumber dan tehnik. Pelaksanaan penomoran menggunakan Family Numbering Filing tetapi tidak ada perbedaan digit nomor untuk anggota keluarga yang dapat dimanfaatkan untuk mengidentifikasi pasien. Sistem Penjajaran rekam medis rawat inap berdasarkan tanggal kunjungan yang dimap per bulan untuk mempermudah petugas dalam menjajarakan DRM. Pemilihan sistem penjajaran karena adanya keterbatasan jumlah petugas, pengetahuan petugas, almari penyimpanan hanya satu buah, keterbatasan ruangan. Simpulan Penyimpanan Sistem Desentralisasi, penomoran Family Numbering System, Penjajaran berdasarkan tanggal kunjungan. Sebaiknya disediakan rak penyimpanan dan Standar Operasional Prosedur tentang penyimpanan dan penjajaran.
\end{abstract}

Kata Kunci: Dokumen Rekam Medis , Pengelolaan, Puskesmas

\begin{abstract}
The administration of medical records management of inpatient medical records at the health center does not yet have a special storage room for medical record documents. The confidentiality of DRM is not guaranteed well because DRM is placed on a cupboard and tied according to the date of visit and the room is easily accessible to everyone. The research objective was to analyze the management of Inpatient Medical Records (IMR) at the Health Center. The research design used is qualitative research. Data collection by interview, observation and documentation study. The validity of the data used triangulation of sources and techniques. Numbering was carried out using Family Numbering Filing, but there was no difference in digit numbers for family members that can be used to identify patients. Alignment system of inpatient medical records based on date of visit which is calculated per month to make it easier for officers to juxtapose DRM. The alignment system was due to the limited number of officers, knowledge of officers, only one storage cupboard, and limited space. Conclusion, Decentralized Storage System, Family Numbering System numbering, Alignment by visit date. It is recommended that storage racks and Standard Operating Procedures on storage and alignment be provided.
\end{abstract}

Keywords: Medical Record, Management, Public Health

\section{Pendahuluan}

Puskesmas merupakan fasilitas pelayanan kesehatan yang menyelenggarakan upaya Kesehatan masyarakat dan upaya Kesehatan perseorangan tingkat pertama, dengan lebih

\footnotetext{
*) Correspondence Author (Harjanti)
}

E-mail: harjantimhk@gmail.com mengutamakan upaya promotif dan preventif, untuk mencapai derajat kesehatan masyarakat yang setinggi-tingginya di wilayah kerjanya (Kemenkes RI, 2014)

Setiap pelayanan kesehatan wajib menyediakan fasilitas yang diperlukan dalam penyelenggaraan rekam medis (Menteri 
Kesehatan RI, 2008). Dalam pelaksanaanya tidak terkecuali Pusat Kesehatan Masyarakat (Puskesmas). Rekam medis adalah bukti tertulis/ catatan (kertas/ elektronik) yang berisikan identitas pasien, pengobatan, pemeriksaan, tindakan dan pelayanan lain yang diberikan kepada pasien yang diberikan oleh Profesional Pemberi Asuhan (PPA) yang wajib dibuat sesegera mungkin dan dilengkapi isinya setelah pasien menerima suatu bentuk layanan kesehatan (Menteri Kesehatan RI, 2008), (Komite Akreditasi Rumah Sakit, 2017), (Sudra, 2013).

Kegunaan rekam medis meliputi aspek administrasi, medis, hukum, keuangan, penelitian, pendidikan dan dokumentasi (Depkes, 2006), (Sudra, 2013). Dengan melihat beberapa aspek tersebut, rekam medis mempunyai banyak kegunaan tidak hanya pasien dan pemberi pelayanan kesehatan, sehingga diperlukan pengelolaan yang baik untuk menjamin ketersediaan rekam medis dan bisa dimanfaat sesuai dengan kegunaanya. Maka untuk meningkatkan kualitas Dokumen Rekam Medis perlu dilakukan audit Rekam Medis secara berkala (Windari et al., 2015).

Puskesmas Jumantono merupakan salah satu Puskesmas yang sudah menyelenggaran rekam medis. Pengolaan rekam medis di Puskesmas Jumantono antara rawat inap dan rawat jalan dipisah. Penanggung jawab rekam medis di rawat jalan sudah dikelola oleh seorang perekam medis namun untuk rawat inap dikelola oleh bidan, hal ini belum sesuai (Permenkes, 2013) yang menyatakan salah satu kewenangan perekam medis yaitu melaksanakan kegiatan pelayanan pasien dalam manajemen dasar rekam medis dan informasi kesehatan.

Pengelolaan rekam medis rawat inap juga belum terdapat ruang penyimpanan khusus untuk dokumen rekam medis. Ruang penyimpanan dokumen rekam medis digabung dengan ruang pelayanan gawat darurat dan ditaruh diatas almari yang disimpan dalam map berdasarkan bulan kunjungan. Sehingga kerahasiaan dokumen rekam medis belum terjamin dengan baik, mengingat semua orang dapat dengan mudah mengakses keluar masuk ruangan termasuk pasien ataupun pengantar pasien. Selain itu kehilangan dokumen rekam medis juga sangat mungkin terjadi dikarena tidak adanya aturan diterapkannya dokumen rekam medis dan buku ekspedisi sebagai bukti peminjaman serta pengembalian dokumen rekam medis.
Tujuan penelitian menganalisis pengelolaan rekam medis rawat inap di Puskesmas Jumantono.

\section{Metode}

Rancangan Penelitian Kualititatif dengan menggunakan triangulasi sumber dan tehnik. Subyek penelitian yaitu Petugas Rekam Medis di Unit Rawat Inap. Obyek yaitu Pengelolaan Rekam Medis di Unit Rawat Inap. Lokasi penelitian di Unit Rawat Inap Puskesmas Jumantono. Penelitian dilaksanakan pada bulan April s.d Juli 2020. Instrumen penelitian dengan menggunakan pedoman wawancara semi terstruktur dan pedoman observasi. Metode pengumpulan data dengan wawancara, observasi dan studi dokumentasi.

\section{Hasil dan Pembahasan}

\section{a. Sistem Penomoran}

Penerapan sistem penomoran di Puskesmas Jumantono menggunakan penomoran Family Numbering system yaitu satu keluarga mendapat satu nomor rekam medis yang sama tanpa ada digit nomor yang membedakan anggota keluarga.

Berikut kutipan wawancara dengan petugas 1:

"Sistem penomoran kita berdasarkan keluarga mbak, jadi kalau ada pasien yang periksa, kita tanya dulu sudah pernah periksa belum nanti kita tanya Kepala Keluarga(KK) nya siapa kita carikan di foldernya berdasarkan KK itu.

Berikut wawancara dengan petugas 2 :

"Penomoran kita pakai family mbak, yang berdasarkan keluarga itu lho.. jadi setiap keluarga mendapatkan 1 nomor rekam medis. Contoh nomor rekam medis 605050 untuk Bp. X dipakai untuk seluruh angggota keluarganya biar gampang. Nanti kartu berobatnya juga hanya satu".

Sistem penomoran tersebut sesuai dengan (IFHIMA, 2012) yang menyatakan sistem penomoran Family Numbering system lebih tepat untuk perawatan klinik primer yang di mana semua anggota sebuah keluarga dapat menerima perawatan kesehatan.

Adapun kelebihan penomoran Family Numbering System di Puskesmas Jumantono adalah untuk memudahkan identifikasi pada 
saat pendaftaran pasien atau pencarian dokumen, serta kartu berobat cukup satu yang dapat dipakai untuk seluruh keluarga yang diharapkan dapat menghemat kertas serta meminimalisir kehilangan. Sesuai dengan (Harjanti \& Wariyanti, 2020) bahwa penomoran Family Numbering System dapat memberikan kemudahan dalam pengambilan dan pengembalian kembali dokumen rekam medis.

Sistem penomoran yang digunakan di Puskesmas Jumantono murni satu nomor dipakai untuk satu keluarga, tidak dibedakan digit untuk menentukan anggota keluarganya. Dari hasil wawancara diketahui agar mempermudah puskesmas dalam pengambilan dokumen rekam medisnya, jika nomor seluruh anggota keluarga sama maka identifikasinya dapat lebih cepat. Hal ini belum selaras dengan (Harjanti \& Wariyanti, 2019) dan (Nurbaya et al., 2020) bahwa sistem penomoran yang berlaku di Puskesmas, satu nomor rekam medis digunakan untuk semua anggota keluarga yang diklasifikasikan berdasarkan kode wilayah dan kode urutan keluarga/ kunjungan. Klasifikasi nomor terdiri dari 8 dan 10 digit yaitu 2 digit angka depan menunjukkan kode wilayah/ kelurahan/ desa, 4 atau 6 digit angka tengah sebagai nomor kepala keluarga pasien dan 2 digit angka akhir sebagai kode urutan keluarga/ urutan kunjungan dalam satu keluarga.

Klasifikasi penomoran pada family numbering system dimaksudkan untuk mengelompokkan nomor sehingga dapat dimanfaatkan untuk mengidentifikasi anggota keluarga mana yang berobat, satu nomor berlaku untuk satu pasien atau bisa disebut dengan unit numbering system. Adapun kelebihan dari system ini yaitu Informasi pasien tercatat dalam suatu kesatuan berdasarkan pelayanan yang diberikan / terintegrasi (Depkes, 2006).

Penggunaan nomor rekam medis pasien dicatat dalam buku register UGD, akan tetapi tidak semua pasien masuk ditulis dalam buku register karena yang mengisi bukan tenaga rekam medis yaitu Bidan yang lebih mengutamakan pelayanan dibandingkan dengan pencatatan data. Kegiatan pencatatan data pasien seharusnya dilaksanakan oleh petugas rekam medis sesuai (Kemenkes RI, 2020) tentang Standar Profesi Perekam Medis dan Informasi Kesehatan dimana tugas seorang perekam medis adalah sebagai pencatat atau pengumpul data pelayanan di rumah sakit dan puskemas. Tetapi di Pukesmas Jumantono petugas rekam medis hanya berjumlah dua orang dan semua ditempatkan di bagian pendaftaran rawat jalan, sehingga buku register rawat inap di UGD ditulis oleh petugas medis.

Pelaksanaan penomoran juga ditemukan penomoran ganda yaitu satu nomor digunakan untuk dua keluarga. Hal ini terjadi karena tidak semua penggunaan nomor tercatat di buku register sehingga nomor tersebut dipakai oleh pasien yang lain. Penerapan buku register belum sesuai dengan (Sudra, 2013) yang menyatakan bahwa buku register berfungsi untuk mengetahui jumlah pengunjung baru ataupun lama yang berobat ke rumah sakit, serta mengetahui informasi mengenai identitas pasien sehingga dapat disimpulan bahwa fungsi dari buku register bukan untuk mencatat penggunaan penomoran.

\section{b. Sistem Penjajaran}

Sistem penjajaran adalah proses menjajarkan dokumen rekam medis dalam rak penyimpanan untuk mempermudah petugas dalam menyimpan atau mengambil kembali (Depkes, 2006). Sistem penjajaran yang diterapkan berdasarkan tanggal kunjungan yang dimap/outner per bulan. petugas I:

Berikut kutipan wawancara dengan

"Kalau kami dokumen kita simpan per bulan mbak sesuai tanggal kunjungan, nanti kami bendel dan ditaruh di outner untuk pasien umum, dan pasien BPJS di bendel saja karena penggunaannya lama. Kami menerapkan begitu biar gampang dan nyarinya cepet karena sudah dibendel per bulan".

Alasan pemilihan sistem penomoran karena adanya keterbatasan jumlah petugas untuk melaksanakan penjajaran, pengetahuan petugas tentang sistem penjajaran rekam medis, almari penyimpanan hanya satu buah serta keterbatasan ruangan.

Berikut kutipan wawancara dengan petugas I:

"Kita tidak menerapkan sistem penjajaran sesuai aturan atau teori karena disini petugasnya tidak ada, raknya tidak ada, ruangan sempit dan 
kita sendiri juga tidak paham menjajarkan sesuai aturan yang benar, yang penting semua disimpan saja".

Menurut (Sudra, 2013) sistem penjajaran rekam medis meliputi :Straight Numerical Filing, Middle Digit Filing, Terminal Digit Filing mana yang paling baik digunakan adalah yang paling cocok dengan situasi dan kondisi mempertimbangkan lemari yang tersedia, tenaga/ petugas yang ada, pola kunjungan dan karakteristik pasien.

Adapun kendala dalam sistem penjajaran yang diterapkan yaitu ada dokumen rekam medis pasien yang masuk kedalam nomor rekam medis milik orang lain sehingga sewaktu dibutuhkan sulit untuk mencarinya. Selaras dengan (Astuti $\mathrm{S}$ et al., 2014) dampak dari penerapan sistem penjajaran yang tidak baku di puskesmas menyebabkan petugas filing kesulitan dalam pelacakan dokumen rekam medis, karena membutuhkan waktu tersendiri untuk menemukan DRM dan waktu pengembaliannya. Selain itu masih ditemukan dokumen rekam medis pasien yang masuk kedalam nomor rekam medis milik orang lain sehingga menyulitkan petugas mencari jika dbutuhkan. Hal ini dapat terjadi karena formulir antar pasien tidak dipisah jadi jika menyimpan dalam outner dapat tercampur antara berkas pasien satu dengan pasien lain.

\section{c. Sistem Penyimpanan}

Puskesmas Jumantono menyimpan dokumen rekam medis secara Desentralisasi yaitu penyimpanan dokumen rekam medis pasien rawat jalan dan rawat inap terpisah. Dokumen pasien rawat jalan di simpan di bagian pendaftaran sedangkan dokumen rawat inap dan gawat darurat disimpan di bagian UGD. Dokumen rawat inap penyimpanannya dibedakan lagi antara pasien umum dan BPJS yang disimpan di almari terpisah.

Berikut kutipan wawancara dengan petugas:

“Sistem penyimpanan kita sendiri sendiri mbak, jadi untuk pasien rawat jalan disimpan di pendaftaran, untuk rawat inap di UGD, cuma di kita cara penyimpanan untuk berkas rawat inap pasien BPJS sendiri Umum sendiri karena ketika ada pemerikaan keuangan dll itu langsung ketemu berkasnya, bulan ini dicocokkan dengan register, klaim, kuitansi. Jadi gampang gitu jadi kita tidak terbebani dengan kesalahan yang mungkin timbul jika penyimpananannya dicampur.

Puskesmas Jumantono belum terdapat ruang penyimpanan khusus untuk Dokumen Rekam Medis. Ruang penyimpanan Dokumen Rekam Medis digabung dengan ruang pelayanan Gawat Darurat dan ditaruh diatas almari yang disimpan dalam Map berdasarkan bulan kunjungan, sehingga kerahasiaan Dokumen Rekam Medis belum terjamin dengan baik. Selain itu kehilangan Dokumen Rekam Medis juga sangat mungkin terjadi dikarena tidak adanya aturan diterapkannya Dokumen Rekam Medis dan Buku Ekspedisi sebagai bukti peminjaman serta pengembalian Dokumen Rekam Medis.

Berdasarkan (Rahmadiliyani \& Faizal, 2018) penyimpanan rekam medis harus dalam keadaan terkunci dan dalam hal akses nya pada ruangan filing hanya memberi wewenang kepada petugas yang berkepentingan seperti dokter, perawat ataupun tenaga medis lainnya untuk melengkapi pencatatan ataupun untuk kepentingan pasien.

Hal ini juga sesuai dengan pernyataan (Hatta, 2014) bahwa kerahasiaan adalah proteksi terhadap rekam medis dan informasi lain pasien dengan cara menjaga informasi pasien dan pelayanannya. Dalam pelayanan kesehatan, informasi itu hanya diperuntukkan bagi pihak tenaga kesehatan yang berwenang. Informasi yang terdapat dalam rekam medis sifatnya rahasia.

Selain itu Puskesmas Jumantono juga belum memakai buku ekspedisi untuk melacak keberadaan dokumen serta bukti peminjaman serta pengembalian rekam medis sehingga jika ada dokumen yang hilang tidak bisa dilacak siapa yang meminjam. Menurut (Depkes, 2006) menyebutkan buku ekspedisi sebagai bukti adanya transaksi/ serah terima berkas rekam medis untuk keperluan pelayanan kesehatan pasien, serta mengurangi resiko kehilangan DRM karena keberadaan DRM dapat terlacak dengan baik. Selaras dengan (Wibawa, 2015) bahwa buku dan catatan yang digunakan dalam pengambilan rekam medis dengan buku ekspedisi yang digunakan untuk mencatat rekam medis yang dipinjam setiap hari. 
Buku ekspedisi yang belum ada dikarenakan kurang pemahaman dan latar belakang Pendidikan Petugas bukan Perekam Mmedis dan Informasi Kesehatan, hal ini sesuai dengan (Ritonga \& Lubis, 2021).

Keterbatasan Penelitian ini yaitu Informan yang bukan merupakan seorang Perekam Medis sehingga kesulitan mendapatkan informasi mendalam tentang pengelolaan Rekam Medis.

\section{Simpulan dan Saran}

Pelaksanan penomoran menggunakan Family Numbering Filing tetapi tidak ada perbedaan digit nomor untuk anggota keluarga. Sistem Penjajaran rekam medis rawat inap berdasarkan tanggal kunjungan yang dimap per bulan. Sistem Penyimpanan rekam medis rawat inap dengan desentralisasi, berkas rekam medis pasien diletakkan diatas almari yang disimpan dalam Map berdasarkan bulan kunjungan. Sebaiknya dokumen rekam medis pasien rawat inap disimpan dalam rak penyimpanan dalam ruangan sehingga kerahasiaan terjaga serta dokumen tidak mudah hilang. Disusunnya aturan/SOP terkait sistem penyimpanan serta ada petugas yang diserahi tanggungjawab terhadap penyimpanan dokumen rekam medis rawat inap agar berkas menjadi lebih teratur serta dapat memantau dokumen yang dikembalikan atau dipinjam. Peningkatan kedisiplinan dalam pengisian buku register agar mudah mengecek data jika terjadi penomoran ganda. Adanya buku ekspedisi agar dapat melacak keberadaan dokumen rekam meds serta bukti peminjaman serta pengembalian.

\section{Ucapan Terima Kasih}

Terima Kasih kami ucapkan kepada STIKes Mitra Husada Karanganyar yang telah memberikan dana. Puskesmas Jumantono yang memberikan ijin untuk melaksanakan Penelitian.

\section{Daftar Pustaka}

Astuti S, R., Kurniadi, A., \& Setyowati, M. (2014). Sentralisasi Pengelolaan Rekam Medis di Puskesmas Binaan Mijen Kota Semarang dalam Menyongsong SJSN di Indonesia. Jurnal Manajemen Informasi Kesehatan Indonesia. https://doi.org/10.33560/.v2i1.37

Depkes. (2006). Pedoman Penyelenggaraan dan Prosedur Rekam Medis Rumah Sakit di Indonesia Rev II Departemen Kesehatan RI 2006.

Harjanti, H., \& Wariyanti, A. S. (2019). Identifikasi Penerapan Family Numbering System di Puskesmas Wilayah Dinas Kesehatan Kota Surakarta. Jurnal Rekam Medis Dan Informasi Kesehatan. https://doi.org/10.31983/jrmik.v2i2.53 46

Harjanti, H., \& Wariyanti, A. S. (2020). Kelebihan dan Kekurangan Penerapan Family Numbering System di Puskesmas Dinas Kesehatan Kota Surakarta. Jurnal Rekam Medis Dan Informasi Kesehatan. https://doi.org/10.31983/jrmik.v3i1.55 54

Hatta. (2014). Hatta, G. R. 2014. Pedoman Manajemen Informasi Kesehatan Di Sarana Pelayanan Kesehatan. Acta Universitatis Agriculturae et Silviculturae Mendelianae Brunensis.

IFHIMA. (2012). Education Module for Health Record Practice Module 3 - Record Identification Systems, Filing and Retention of Health Records. 1-28.

Kemenkes RI. (2014). Peraturan Menteri Kesehatan (Permenkes RI) Nomor 75 tahun 2014 tentang Puskesmas. In 24 April.

Kemenkes RI. (2020). Keputusan Menteri Kesehatan Republik Indonesia No. 312 tahun 2020 tentang Standar Profesi Perekam Medis dan Informasi Kesehatan. 42.

Komite Akreditasi Rumah Sakit. (2017). SNARS edisi 1. In Standar Nasional Akreditasi Rumah Sakit.

Menteri Kesehatan RI. (2008). Permenkes RI No. 269 Th. 2008. In Menteri Kesehatan.

Nurbaya, F., Okta, Y. A., \& Kurnia, B. (2020). Gambaran Pengelolaan Dokumen Rekam Medis di Puskesmas X. Jurnal Manajemen Informasi Dan Administrasi Kesehatan (JMIAK). https://doi.org/10.32585/jmiak.v3i01.7 03

Permenkes. (2013). Peraturan Menteri Kesehatan Nomor 55 Tahun 2013 tentang 
Penyelenggaraan Pekerjaan Perekam Medis. In Jakarta : Departemen Kesehatan Republik Indonesia.

Rahmadiliyani, N., \& Faizal, F. (2018). Kerahasiaan Rekam Medis di Rumah Sakit Aveciena Medika Martapura. Jurnal Manajemen Informasi Kesehatan Indonesia. https://doi.org/10.33560/.v6i2.189

Ritonga, Z. A., \& Lubis, H. E. (2021). Tinjauan Pelaksanaan Sistem Penyimpanan Rekam Medis Berdasarkan Standar Akreditasi DiUPTDPuskesmas Kotanopan Mandailing Natal. 6(1), 14-22.
Sudra, R. I. (2013). Rekam Medis (S. Nurhayati (ed.); Kedua). Universitas Terbuka.

Wibawa, O. A. (2015). Tinjauan Sistem Penomoran di TPP RS BHAKTI WIRA TAMTAMA Semarang Tahun 2015. Eprints.Dinus.Ac.Id.

http://mahasiswa.dinus.ac.id/docs/skr ipsi/jurnal/15988.pdf\%0Ahttp://eprint s.dinus.ac.id/17386/

Windari, A., Kristijono, A., \& Umboro, L. (2015). Gambaran kelengkapan Dokumen Rekam Medis Pasien Rawat Inap. LINK, 11, 897-901. 